\title{
Explaining the Relationship between Religiosity and Increased Wellbeing Avoidance of Identity Threat as a Key Factor
}

\author{
Authors \\ Rita Phillips, Mark Burgess, Vincent Connelly
}

\begin{abstract}
Previous research outlines a relationship between religiosity and increased mental and physical wellbeing. However, to date findings from quantitative and qualitative research do not offer an unambiguous explanation for this relationship. The study addresses this gap in knowledge by examining underlying identity construction processes in relation to religiosity and wellbeing in the light of Identity Process Theory (Breakwell, 1986, 2001, 2010). Eight Christian converts from different deep-faith groups were recruited via purposive and modified snowball sampling. Detailed descriptions of first-hand experiences were collected by biographic-narrative interviews and analysed by Interpretative Phenomenological Analysis. The findings suggest that religious elements are integrated into identity content as these respond to a set of motivational principles of identity construction. In doing so, religious elements in identity content contribute to the avoidance of identity threat and to the maintenance of a positive identity structure. The adoption of healthpromoting behaviours that relate to the application of beliefs (i.e. practice forgiveness, love oneself and the other, stopping excessive drinking) are consequences thereof and improve mental and physical wellbeing. In conclusion, the relationship between religiosity and wellbeing may be explained by the way in that religious elements in identity impact on identity maintenance process.
\end{abstract}

Keywords

Religious groups, Religious conversion, Identity process Theory, Identity threat, Wellbeing 


\section{Introduction}

Previous research indicates that religiosity impacts wellbeing positively. For example, religiosity was found to stand in relationship with increased mental health (Koenig, McCulloug, 2001; Loewenthal, 2007; Unterrainer, Lewis and Fink 2014) and physical health (Jim et al. 2015, Paiva Ribeiro Paiva, Yennurajalingam and Hui 2015). To explain the health promoting effect of religiosity, previous research investigated the impact of external religious factors such as attending religious ceremonies, and, intrinsic religious factors, such as praying alone. However, the results from predominantly quantitative studies that examined and compared the effect of external and intrinsic religious factors are ambiguous and contradictory. Some studies identify external but not intrinsic factors relate to increased mental health and wellbeing (i.e. Okulicz-Kozaryn, 2010; Putnam, 2001), while others outline intrinsic but not external factors to have health promoting effects (i.e. Ayele, Mulligan, Gheorghiu \& Reyes-Ortiz, 1999; Salsman et al., 2005). Although, minor differences in sample population and instrument may account for some of this ambiguity, the differences remain largely unexplained.

By considering identity in relation to religion and wellbeing, theoretical perspectives on identity take underlying reasons for the positive effect of religiosity on wellbeing into account and demonstrate that religious identities might provide additional support to stabilise one's identity in times of identity-disruption (c.f. Loewenthal 2014, Vignoles, Chryssochoou \& Breakwell, 2002, Jaspal and Cinnirella 2010). The relationship between religiosity and increased wellbeing would therefore be the consequence of identity-threat avoidance. Blaine \& Crocker (1995) support this claim in their study on the salience and value of religious identities and the effects of these on the psychological wellbeing in relation to ethnicity and gender. Their results suggest that increased wellbeing may relate to religious identity as it provides a sense of security and sameness with oneself at times where other important identities are threatened. More concretely, black college students who disidentified with achievement values as a defence against racial stigma, maintained wellbeing by identifying more strongly with their religious community than whites (Blaine \& Crocker, 1995; cf. also Loewenthal, 2014). This exemplifies how the re-evaluation of identity content may contribute to stability in identity, and in doing so, to wellbeing. Studies that examined identity in times of transition and threat outlined similar results. Coyle (2011), for example, demonstrates an increase in the value of religious identity in response to occupational threats. Walters \& Auton-Cuff's (2009) who examined transition disrupted identity development in third-culture children point to religious identities as promotinga feeling of stability and thus to wellbeing as a consequence thereof. In conclusion, religious identities may increase wellbeing as these facilitate the avoidance of identity threat. 
However, to date detailed knowledge about the way in which religious identities may facilitate coping with identity threat is scarce. Therefore, it remains questionable how religious identities may resonate with identity construction processes that are essential for maintaining a positive identity structure.

Identity Process Theory (IPT; Breakwell, 1986, 2001, 2010) may be a theoretical framework that explains the relationship between religiosity and wellbeing further as IPT allows the examination of ongoing processes in identity construction. Essentially, identity is theorised in IPT as a composition of structured, hierarchical content with elements shifting in their centrality. Therefore, social elements such as religious or other group memberships and individual elements of identity are non-distinct features of identity content that may shift temporarily or permanently in their importance (cf. Pehrson \& Reicher, 2014). Shifts in importance of identity content, however, do not happen randomly but can be predicted by a set of motivational principles: (1) continuity between past and present self-concepts (continuity), (2) personal uniqueness (distinctiveness), (3) confidence and being in control over one's life (self-efficacy), (4) personal worth (self-esteem), (5) feelings of closeness and acceptance by others (belonging) and (6) finding a significance and purpose in one's life (meaning; cf. Twigger-Ross \& Uzzel, 1996; Jaspal \& Breakwell, 2014). Essentially, a core prediction of IPT is that if these six principles cannot be satisfied and thus fail to comply with the assimilation, accommodation and evaluation of identity content, then an identity is threatened (Breawell, 1986, 2001, 2010). This means that an individual cannot maintain a positive identity structure and will engage in strategies to cope with the threat that include inter alia the adaption, re-evaluation and adoption of new identity content (cf. Jaspal \& Breakwell, 2014).

To summarise, religious elements in identity content may shield individuals from the identity threat threatened when the six principles of identity construction of continuity, distinctiveness, self-efficacy, self-esteem, belonging and meaning cannot be satisfied. Situations in which the individual would experience identity threat may therefore be alleviated by religious elements in identity content and wellbeing maintained. However, as the religious elements in identity content in relation to these six principles of identity construction have not yet been examined their relationship remains unclear.

We address this gap in knowledge by examining the process in which religious elements in identity are adopted and valued in relation to the six principles of identity construction. In doing so, the focus will be on religious converts pre- and post-transition identity. Their reflections 
may illuminate how religious elements in identity resonate with the six principles of identity construction. To ensure the depth of religious belief, the present study focussed on recruiting individuals who prayed for at least one hour per day.

\section{Methods}

A qualitative methodology is used to examine the connection between religious elements in identity, principles of identity construction, avoidance of identity threat and wellbeing. Eight participants were recruited to examine the subjective experience of the significance of religious elements in identity and their impact on identity processes. This sample size is commonly considered to be an appropriate sample size to allow in-depth examinations of psychological thinking patterns and understandings (Patton, 1990; Groenewald, 2004; Holloway \& Wheeler, 2002) by interpretative phenomenological analysis (IPA, Eatough \& Smith, 2008). Although there are no strict rules, qualitative research commonly considers five to eight participants to be sufficient for a study that examines subjective experiences (Shaw, 2004; Holloway \& Wheeler, 2002).

After retrieving ethical approval from Oxford Brookes University, purposive and modified snowball sampling was used to recruit participants. In first instance, the project was advertised at different international Christian events to which the researcher had access. Initially, five individuals responded to the advertisement and participated in the study. With the aim of recruiting a diverse sample (e.g. differences in nationality, denominations, age, gender, etc), a modified snowball strategy was used. Therefore, the sample was expanded by asking the participants to invite others to conduct the study (Crabtree \& Miller, 1992). In this way, three additional participants were recruited. All eight participants who were between 2155 years old self-identified as religious converts who experienced a religious transition in the last 10 years. Of the eight participants, five participants belonged to charismatic groups/organisations within the Catholic Church and three to charismatic Free Churches.

The first participant, Sam (all participants names are pseuodonyms), contacted the researcher via email after the project was advertised at a New Zealand Catholic Charismatic Centre. Sam is a 35-year-old Indonesian who converted 10 years ago after suffering from domestic violence and an unstable family situation. Sam works now at the Catholic Centre, leading discipleship courses for 18-25 year old internationals. Jim, Eliza and Dan contacted the researcher after the project was advertised at a Catholic Pentecostal youth festival. Jim is a 21-year-old Austrian student, who converted 5 years ago. He started to believe and to pray 
after his mother was diagnosed with terminal breast cancer. Although his mother died two years after the diagnosis, he continued to have strong faith. Eliza, a 26-year-old Austrian postgraduate student, converted during her exchange semester abroad three years ago. During her exchange year, she experienced a deep loneliness that lead her to faith. Dan, a 30-year-old German converted 5 years ago. He described how he grew up in a German "ghetto", dropped out of school, was a gang-member and engaged in substance abuse, stealing and heavy drinking before his conversion. After being a missionary in Africa, he got married and works as a manager of a sales company.

Three participants contacted the researcher by email after information about the study was passed on by the word of mouth. Jane was a 32-year-old Austrian who converted 7 years ago. Before her conversion, Jane went through a serious depression and eating disorder related to the experience of domestic violence in her childhood. She is now married and a full-time housewife, looking after her three children. John, a 54-year-old missionary converted 8 years ago. John, who had been an established broker and accountant, converted when he was imprisoned for money washing and trading with the Mafia and Mexican Drug-Cartels. After he was released, John founded a ministry and is now travelling through Germany to preach the gospel. Zoe, a 22-year-old Psychology student converted during her first year at University, 2 years ago. At that time she suffered from an existential crisis and engaged in heavy-drinking, smoking and substance abuse. She converted following an experience at a Christian festival that she attended by chance. Zoe joined a Christian Discipleship Programme in New Zealand that she attends to this day. The last participant, Lisa, is a 25 -year-old vet in training. Lisa studied at a University in New Zealand and converted during her first year at University, 2 years ago. In her childhood, Lisa suffered from her parent's divorce and later from a severe undiagnosed illness that made it difficult for her to make friends. She became bitter, angry and sad. After she started University, Lisa attended a Pentecostal event during which she made an experience which enabled her to let go of her anger, bitterness and sadness. As a consequence, she converted to Christianity. To collect descriptions of the participants' first-hand experiences and their reactions to those experiences, biographic narrative interviews (Wengraf, 2001) were utilised. Eight face-to-face interviews were conducted individually, each of them lasting between 100 and 170 minutes. The interview schedule was structured in three sub-sessions. In the first stage, participants are prompted to speak freely about their religious conversion. Therefore, the initial question (SS1) intends to open up a narrative history ('Could you tell me everything about the time of your religious transition? Please do not feel distracted by me taking notes of you. I do that in order to ask you some questions in the second stage.') 
The second part consists of questions surrounding the participants' responses from the initial question (SS1). These follow-up probes (SS2) encourage to elaborate information related to the area of the study's interest further to clarify the respondent's meanings (i.e. 'you mentioned that you felt "true”. Could you explain what this means?'; cf. Eatough \& Smith, 2008).

The final sub-section (SS3) comprised specific questions, based on pre-existing knowledge, by integrating information from the reviewed literature (i.e: 'could you explain how religiosity helped you .. An example therefore would be: 'Which role does God and experiences explicitly related to him play when you think of increasing happiness or satisfaction with your life?'

The interviews were conducted by the first author during an 8-month time period between May $15^{\text {th }} 2016$ and January $10^{\text {th }} 2017$. Interviews were conducted in either English or German by the first author. The first author is a native speaker of German and is fluent in English. The first author transcribed the German and English interviews and they were sent to the participants for checking. After the participants made some minor changes and sent the corrected version back, the German interviews were translated by an accredited translator into English to ensure complete accuracy. The names of the participants were anonymised and allocated pseudonyms. Each transcript was analysed individually by IPA (Eatough \& Smith, 2008). IPA was found to be the most suitable method as it examines the holistic meaning of phenomena through the description of subjective perceptions (cf. Gavridis, 2004). By the researcher's attempt to describe the content of the data, and, in a further step, its psychological significance and key psychological constructs, emerging key themes were identified. This made it possible to reveal the underlying psychological meaning behind the respondents' answers and facilitates to group thinking patterns and perceptions into categories. This allows the researcher to interact in an interpretive way at this stage, whilst interpretations remained grounded in the respondents' answers.

\section{Results}

\section{Pre-Conversion Identity Threat}

In line with previous research, the present study outlines specific pre-involvement factors to contribute to religious conversions. For example, psychological distress, crisis or a period of transition, family relationship problems and abuse are all significant topics in the participants' accounts (cf. Barker, 1984; 2006; Saroglou, Christians, Buxant \& Casalfiore, 2006; Buxant, Saroglou, Casalfiore \& Christians, 2007; Dawson, 2003; Richardson, 2007; Coates, 2011). 
However, from an IPT perspective, the findings suggest that these pre-involvement factors may be indicative for a pre-existing identity-threat. Therefore, previously identified pre-involvement factors such as psychological distress, transitions etc. may frustrate the operability of at least one principle of identity construction continuity, distinctiveness, self-efficacy, self-esteem, belonging and meaning. The present findings support this by outlining that pre-involvement factors respond to reciprocal interactions of the identity principles. Zoe, for example, when describing her conversion during her first year at university explains:

'I was very distant from my family. [...] I tried really hard to create for myself, like a life that I was proud of. And so I made a lot of friends [...] I think really just to find myself. Find my worth in seeing how my friends saw me as good, or in how I dressed. [...] My thought was: I have friends because it's safer to have friends at university. And, like, in the end, I realized that I was just very alone. Like there was nothing, no safety in the end for me because my friends were friends with me for a reason. [...] At this point I really started to question. Like what it means to... what it means to live.'

Zoe's quote exemplifies how a significant life transition can impact the operability of identity principles. In Zoe's case, moving away from home challenged re-evaluating family-related elements in her identity, affecting her sense of belonging. Similar quotes that thematise an absence of belonging and loneliness were identified in all the participants' accounts. In this sense, an absence of belonging had different dimensions: Moving away from home (Eliza, Lisa), being imprisoned (John), feeling rejected in everyday interactions following an abusive or impoverished childhood (Jane, Sam), or, feeling alone in dealing with the illness of a loved one (Jim). However, essentially, an unsatisfactory response to the identity principle belonging had a spill over effect on other principles of identity construction. For example, the absence of prescribed roles in that Zoe's identity was rigidly defined questioned identity-continuity as persistency in her self-concept could not be maintained. In an attempt to re-evaluate the identity content, social connections were over-emphasised to maintain appreciation and self-esteem. However, instead of shielding participants from identity threat, an over-identification with social relationships led to unsatisfactory responses to the principle distinctiveness and meaning. Jane, who suffered from depression and an eating disorder before her conversion, explains:

'At that time I was no person. I, myself, had no characteristics, no hobbies, nothing. The hobbies, the opinions and all characteristics of this person, the others knew as Jane, were adopted from other people whom I respected. Psychologically I was at a dead end. Actually I was dead, psychologically. I felt like I was not loved by anyonenothing fulfilled my real desire, to be loved [...] I lost my will to live and with losing the will to live I lost happiness completely. On one day I just stopped eating because life had no meaning to me.' 
This quote exemplifies, how seeking appreciation through diminishing personal uniqueness and distinctiveness results in a loss of meaning. Jane's attempt to find belonging through rejecting elements of her identity responded to the principle of self-esteem superficially, leading to an absence of depth and meaningfulness. This 'empty feeling inside' (Luke) was commonly conceptualised as 'holes of desire' (Dan) that the participants 'tried to fill with trash' (Dan), or, more concretely, with what a perceived secular society suggests will make participants happy. For example, Dan, who was part of an ethnic-gang before his conversion elaborates:

'A wild life was perfectly normal for me. Just as society proclaims: You only live once - act everything out, experience everything, make new experiences no matter whether good or bad. And that's what I did-cause I was part of the gang [...] I partied a lot, much alcohol was involved. I tried everything, drugs, drug-related crime and stuff like that.'

This quote exemplifies how social circles set the boundaries for acceptable behaviours.

Essentially, understanding actions in relation to sub-cultural norms and expectations diminish one's agency over these actions. As a consequence, self-efficacy could not be maintained as the control over one's life and decisions could not be exercised. Therefore, the results indicate that the stronger belonging, self-esteem and continuity were satisfied through identification with a group, the less self-efficacy participants perceived to have in their situation. Whether these groups were the 'High Society' (John), 'Besties from School' (Jim), 'the Gang ' or a 'very demanding family' (Eliza) mattered little.

The findings suggest that all participants experienced identity threat prior to conversion as identity construction processes were frustrated. Therefore, a positive identity structure could not be maintained as the principles of identity construction did not operate satisfactorily. Preinvolvement factors such as periods of transition, psychological distress, family relationship problems etc. (cf. Barker, 1984; 2006; Saroglou, Christians, Buxant \& Casalfiore, 2006; Buxant, Saroglou, Casalfiore \& Christians, 2007; Dawson, 2007; Richardson, 2007; Coates, 2011) were therefore indicative for identity threat (cf. Jaspal \& Breakwell, 2014). Thus, the adaption and adoption of new identity content was a logical consequence thereof.

\section{Reconceptualization of Identity Content and Integration of Religious Elements}

The results indicate that religious elements in identity were adopted and emphasised as these contributed positively to underlying identity construction processes by responding to the six identity principles. Essentially, all accounts indicated that an encounter with God was the 
stepping stone for accepting and emphasising religious elements in their identity. Essentially, the unconditional love that the participants experienced and ascribed to God affected selfperceptions by raising appreciation and self-esteem, as Jane describes:

'The authentic me was not worth to be loved. [...] I have never experienced to be loveable. I hated myself.[...] During [the first] confession something happened. I don't know what - I cannot really describe it. I came out of the room and started crying. I couldn't stop - I cried and cried and I did not know why exactly. I had this overwhelming feeling, somehow as if I wasn't myself anymore. [...] I experienced this healing from the twofold me, which made me one again. I perceived love from my heavenly father - I can be happy with myself!'

In this quote, Jane exemplifies how the experience of unconditional appreciation and acceptance plays a pivotal role in changing the participants self-concept. Whether at a confession (Jane, Eliza), a Christian prayer group meeting (Dan, Sam, Lucy, Zoe, Jim) or in prison (John), all participants reported similar highly emotional experiences and responses towards these experiences. In this sense, the feeling of being beloved even 'when you are weak, hurt and sad' (Jim) or 'weak and vulnerable' (Eliza) provided self-worth and thus selfesteem that were justified by accepting theological doctrines of God's omnipotence. Dan explains:

'You know every other religion - well not the monotheistic ones - but all the other rubbish - people choose their own path by themselves. But since He created us, God chose us. That gives us a completely different kind of orientation.'

This quote exemplifies how the acceptance of theological doctrines followed the experience of unconditional love that responded to the identity principle self-esteem. Here, Creationism played a particular role. Essentially, the belief that the universe originates with acts of a divine being justified to the participant their belief at being a chosen, unique individual that has a purpose in life. Besides resonating with the identity principle distinctiveness and meaning, Creationism may also provide a sense of stability and consistency in conceptualisation of the own 'self'. More concretely, self-conceptualisations as a created being allowed the participants to associate specific inherent, original characteristics to themselves that are known by the creator ('He created you in an original way. Then that became like the answer to who I am.' Zoe; 'He [God] created you in an original way. So, I have got to be the original, true me, which is good, loving and caring because this is the way how I have been created' Eliza). In this sense, Creationism may have responded to the identity-principle continuity and was therefore integrated into identity-content.

Religious elements in identity thus satisfied the principles of identity construction self-esteem, distinctiveness, meaning and continuity, with the participants engaged in re-evaluating identity 
content. Here, a particular focus on authenticity justified acting differently than expected even in highly scripted social situations that would require adhering to specific in-group behaviours. Dan continues to explain:

'Because once I knew that my father in heaven loves me, I realised that it doesn't matter that other people might not love me as I am. He loves me as I am. I don't have to be strong or bad any longer - this is no longer of interest. If someone doesn't love me as I am - I still love them.'

This quote exemplifies how the emphasis on religious elements in identity provided distance to socially expected behaviour. The subsequent loss of social state and in-group recognition, however, did not pose a threat to identity as religious elements in identity content satisfied the principles of identity construction. Therefore, the re-evaluation of identity content and the disidentification with social groups resonated also with the principle self-efficacy as in-group specific and socially expected behaviours were conceptualised as less binding (i.e. 'You always are aware that you're free, so you can say yes, you can say no.' Zoe; 'Today it [opinion of friend] does not matter to me at all anymore. It's called not being dependent on fear of people but being dependant on fear of God.' John). As a logical consequence thereof, individuals exchanged their perceived mundane social circles with religious peers who shared their perception of reality. This, however, happened gradually and all participants reported they maintained some friends who were not religious. Luke elaborates:

'You know having secular and spiritual friends was like running back and forth from one world to another. I still have very good friends who are non-believers [but] I don't need these pretend-to-be-cool friends anymore. In the beginning you still have this desire, though. And you want to go clubbing and have parties. I think that's normal. But I spend more time praying, so it is very natural that you make friends and places where you are more often.'

This quote outlines how changing friends and social circles may happen as a natural progression of identity reconceptualisation. Therefore, the results do not suggest that these participants involvement in strong-faith groups may be the result of deceptive recruitment or brainwashing (cf. Aronoff, Lynn \& Malinoski, 2000). Instead, the involvement in strong-faith groups of many individuals may coincide with the re-formation and -evaluation of identity content. The data suggests that religious groups are important in religious-conversions and resonate with the identity principle belonging, however, only to the extent that the group embodied the ideologies and attitudes it communicates. Jane explains:

'The friendship was like a magnet, it attracted me, it had this divine, unconditional aspect of love.[...] I could not say that I had a very best friend or a person that was extraordinarily important to me. Students came and went, faces changed, but there was an underlying essence of this community, perfect love, lived in this community. 


\section{[...] People were coming and going. But the Christian lifestyle remained.}

In this sense, religious groups became a "termed personification" (Joffe, 2007, p. 206), a concrete and graspable reality that represents abstract and intangible concepts. Jane therefore characterises the Christian lifestyle by appreciation, respect and care for each other that she experienced in this religious group. Similarly termed personifications were identified in all narrative accounts, characterising Christian groups as extraordinarily welcoming (i.e. 'offering you tea and coffee, biscuits and sweets 'Jim), polite ('everybody is happy and smiling, they want you to be first in the queue' Eliza) and caring ('When I had questions, which were important to me, they took the time and spoke with me about it. 'Sam).

This would suggest that defined theological concepts and beliefs are integrated into identitycontent when they resonate with the principles of identity construction. Therefore, the new belief system that focused and emphasised religious aspects of identity content shielded participants from identity threat as the religious aspects of identity content satisfactorily responded to the principles of identity construction. This allowed participants to maintain a positive sense of self.

\section{Impact of Religious Elements in Identity Content on Wellbeing and Health Behaviours}

The focus on religious elements did not only shield identity from identity threat but in doing so also promoted mental and physical health behaviour. Religious education, reflection and spiritual growth were identified as key actions that, motivated by the acceptance of religious elements in identity content, led to greater self-perceived wellbeing. For example, Eliza explains

'I started to pray a lot and try to find him. Sometimes it was like hide-and-seek in a way. Sometimes he took my hand and touched me and I felt him. But then sometimes I could not feel him and I start looking for him in my heart. And while I am looking for him, I figured out what went wrong in my life and what made me unhappy. Like he would be hiding behind ... for example my memories of binging [binge-eating disorder] or of sleeping around and say something like: "Did it make you happy? How did you feel and why did you feel like that? What went wrong?" And I start thinking: "Gosh, that was wrong! That hurt my soul quite a bit."'

Here, Eliza gives an example of an internal monologue that allowed her to reflect on negative experiences and frame them more positively. In this sense, taking a religious perspective facilitated the processing of memories and the recognition of harmful or undesirable effect of behaviours but without taking a self-condemning attitude. Instead, self-forgiveness through 
divine forgiveness was an important notion that had a spill over effect also on participant interpersonal relationships. Essentially, the experience that own wrongdoings could be forgiven changed the participants' perspectives and resulted in them forgiving others. Lucy elaborates:
'I had all that experience of forgiving myself about all the bad things in my past like running away, drinking, drugs, smoking. I asked the Lord for forgiveness and I realized that the list of my wrong-doings went on and on. [...] And after I received forgiveness, it clicked on me that I can't hate dad. Because when I hate dad, I can't forgive also myself for everything I did wrong. But Jesus loves the sinner. So there was this outpoor of my past. How I was bitter to my dad and bitter to my life. Suddenly all these negative emotions were just not there anymore and I just felt calm and at peace and forgiving and positive.'

This quote outlines the complex interaction between perceived self-forgiveness, divine forgiveness and interpersonal forgiveness. Essentially, self-forgiveness and interpersonal forgiveness followed the same structure (cf. Gamlund, 2014). At first, genuine repentance for own wrongdoings without attributions of bad faith was displayed. This context was characterised by an absence of shame or blame and allowed participants to experience divine forgiveness and resulting self- and interpersonal forgiveness. In this sense, the absence of shame and blame was a crucial factor for self- and interpersonal forgiveness. A religious perspective therefore initiated participant psycho-hygiene processes and restored the capability to carry on as functioning person even after being previously perceived responsible for wrongdoings or being a victim of wrongdoings and so allowed them to let go of negative experiences (cf. Griswold, 2007). As John explains, this evoked the feeling of deep joy:

'I saw everything I had done [criminal actions], I saw it in front of me as it all crumbled away. It was all gone. [...] I was let out of my prison cell [for the morning roll-call] and I hugged and kissed everybody saying: "Do you know how wonderful it is here in prison? God loves you and I love you too!" [...] This joy was so deep. It was from within, it was so powerful - it did not disappear on Monday, Tuesday,

Wednesday ... This joy was there and it has stayed until today.'

This quote exemplifies how John achieved coping through dealing with the environment by changing his self-perceptions and attitudes. In this context, forgiveness appeared to cause a cathartic release of happiness. The permanence of this happiness, however, can be explained by the permanence in John's change of self-perception and attitudes. As religious elements were integrated into his identity content and emphasised, happiness that was evoked through aspects of these elements (divine forgiveness, unconditional acceptance) were also maintained and experienced. In this sense, all participants characterised their post-conversion life by 'more bright and positive' (Sam), 'unbelievable easiness and freedom' (Jane) which enabled 'to laugh more because life becomes easy' (Jim). As a consequence of these positive feelings, the 
unconditional acceptance and appreciation that the participants experienced were also projected onto an inter-personal level. Dan elaborates:

I stopped living this useless life of chasing - of filling the holes in my soul with parties, money, work and women. I accept people as they are and try to love them. I fight a lot less and treat people with love - and this love often is being returned.'

The present quote exemplifies how the application of belief promoted interpersonal relationships and individual health behaviours. Therefore, the committed to faith stimulated pro-social behaviour and improved poor health habits such as smoking, excessive drinking and eating disorders were improved. This is aligned with previous research that suggests the positive effect of religious coping on physical and mental health to depend on the application of religious ideologies (Pargament, Koebig \& Perez 2000).

\section{Discussion}

The present study utilized IPT (Breakwell, 1986, 2001, 2010) to outline how pre-conversion identity threat may lead to a reconceptualization of identity content in Christian converts. Religious elements may be integrated into identity content as they responded to this identity threat. In this sense, the results suggest that religious elements in identity content in Christian converts may satisfy the six principles of identity construction (continuity, distinctiveness, selfesteem, self-efficacy, belonging, meaning; cf. Jaspal \& Breakwell, 2014). Once acquired, religious elements in identity content may be strongly emphasised as operating situationally and contextually independent in responding to the principles of identity construction. Therefore, religious elements in identity content may facilitate the avoidance of identity threat on a permanent base by securing the operability of underlying identity maintenance process. In this sense, religious elements in identity content may have a positive effect on mental wellbeing, certainly in Christian converts, and perhaps also in others. More concretely, the application of beliefs that were contained in the religious elements of Christian converts promoted mental and physical health behaviours such as forgiveness, letting go of negative experiences and abstaining from excessive drinking or smoking.

This study emphasises the value of research that examines identity in relation to religion and wellbeing (i.e. Loewenthal 2014; Blaine \& Crocker, 1995; Coyle, 2011; Walters \& Auton-Cuff, 2009). The theoretical backdrop of IPT (Breakwell, 1986; 2001, 2010) extended the state of existing knowledge by offering a perspective to examine the process of integrating religious elements into identity content, the motivational principles behind this process and the 
consequences thereof. In this sense, the present results may also explain why previous research was ambiguous in determining whether extrinsic or internal factors improved wellbeing (cf. Okulicz-Kozaryn, 2010; Putnam, 2001; Ayele et al., 1999; Salsman et al., 2005). The present results suggest that both, extrinsic religious factors such as attending religious ceremonies and internal religious factors such as praying alone, may contribute to greater physical and mental wellbeing. This is the case as external and intrinsic religiosity may be mere expressions of elements in participant identity content. However, the extent to which religious elements in identity content may impact on wellbeing may depend on their assigned significance. In this sense, measuring external and intrinsic factors without examining the assigned significance of the religious elements in identity may have little explanatory power, especially in those with a strong religious identity.

However, although the results have provided an exhaustive analysis of identity processes in relation to wellbeing, a number of caveats need to be taken into consideration. As a qualitative study with a small sample size, the present study is limited in its ability to be generalised (Morris \& Higgs, 2006). This caveat is particularly important in the context of the recruited population as all participants were members of Charismatic Communities and with a snowball sample were very much like minded participants. Members of Charismatic Communities can be seen as a sub-culture within a religious Catholic/ Evangelical/ Free Church subculture and, as such, a minority of individuals who identify with a religion and the results of this study may not be generalisable to the whole of a population identifying with a religion. Additionally, it remains possible that similar accounts could be obtained from individuals who enthusiastically follow other religions or ideologies such as identifying with a football team or one's national identity. This raises the interesting possibility that similar processes may underpin also the identity conversion in other areas of life and which future studies may want to address.

However, while these caveats need to be taken into consideration, the present study's main intention concerned adding explanatory potential to improve the understanding of the relationship between religiosity and wellbeing by deconstructing identity processes. Although the present results may therefore not be generalizable and future research is necessary to understand potential differences between religious and other identity-relevant ideologies, the present study points out underlying processes that need to be considered in future research.

Another limitation concerns the retrospectivity of the participant's accounts. As the present project relies on the reconstruction of the converts' experiences, their accounts are interpretative and influenced by the respondents' present situation (cf. Robbins, 1988). Thus, in trying to make 
sense of their experiences, the respondents accounts may have been flawed by interpretative biases. However, this is a common problem in qualitative research more generally as reporting on subjective experience always relies on the respondents' retrospective accounts.

Lastly, it needs to be noted that the researcher had chosen to select and arrange certain themes based on how understandings of identity threat can be explained. In doing so, it could be suggested that some of the phenomenological values have been undermined by seeing participants' understandings not through their 'eyes' but through a 'bi-focal lens' (the participant's and the researcher's) or a 'tri-focal lens' (the participant's, the researcher's and the theory's; cf. Bryman, 2003). In observing this, it becomes questionable whether the participants' 'voices' have been sufficiently well heard.

Despite these limitations, this study offers a new perspective by relating IPT to religiosity and wellbeing. Although it is not suggested that IPT provides the only approach to investigate the relationship between religiosity and wellbeing, it was found to be a useful framework with which this relationship could be examined more exhaustively.

\section{References}

Aronoff, J., Lynn, S. J., \& Malinoski, P. (2000). Are cultic environments psychologically harmful?. Clinical Psychology Review, 20(1), 91-111.

Ayele, H., Mulligan, T., Gheorghiu, S. \& Reyes-Ortiz, C. (1999). Religious activity improves life satisfaction for some physicians and older patients. Journal of the American Geriatrics Society, 47(4), 453-455.

Barker, E. (1984). The making of a Moonie. Oxford: B. Blackwell.

Barker, E. (2006). Bryan Wilson's contribution to the study of the New Religious Movements. Social compass, 53(2), 147-153.

Blaine, B., \& Crocker, J. (1995). Religiousness, race, and psychological well-being: Exploring social psychological mediators. Personality and Social Psychology Bulletin, 21(10), 1031-1041.

Breakwell, G. M. (2001). Mental models and social representations of hazards: the significance of identity processes. Journal of Risk Research, 4(4), 341-351.

Breakwell, G. M. (2010). Resisting representations and identity processes. Papers on social representations, 19(1), 6-1.

Breakwell, G. M. (2015). Coping with threatened identities. London: Methuen. 
Bryman, A. (2003). Quantity and quality in social research. Oxon: Routledge.

Buxant, C., Saroglou, V., Casalfiore, S., \& Christians, L. L. (2007). Cognitive and emotional characteristics of New Religious Movement members: New questions and data on the mental health issue. Mental Health, Religion and Culture, 10(3), 219-238.

Coates, D. D. (2011). Counselling former members of charismatic groups: considering preinvolvement variables, reasons for joining the group and corresponding values. Mental Health, Religion \& Culture, 14(3), 191-207.

Coyle, A. (2011). Critical responses to faith development theory: A useful agenda for change?. Archive for the Psychology of Religion, 33(3), 281-298.

Crabtree, B. F., \& Miller, W. L. (1992). Doing qualitative research. Research for Primary Care. Newbury Park: Sage.

Dawson, L. L. (Ed.). (2003). Cults and new religious movements: a reader (p. 297). Oxford: Blackwell.

Eatough, V., \& Smith, J. A. (2008). Interpretative phenomenological analysis. The Sage handbook of qualitative research in psychology, 179, 194.

Gamlund, E., 2011. Forgiveness without blame. In: Fricke, C. (Ed.), The Ethics of Forgiveness - a Collection of Essays. New York and Oxfordshire: Routledge.

Gavridis, M. (2004). Hermeneutics and Psychotherapy. Existential Analysis: Journal of the Society for Existential Analysis, 15(2).

Griswold, C.L., 2007. Forgiveness - a Philosophical Explanation. Cambridge University Press, New York.

Groenewald, T. (2004). A phenomenological research design illustrated. International journal of qualitative methods, 3(1), 42-55.

Holloway I., \& Wheeler, S. (2002), Qualitative Research in Nursing (2 ${ }^{\text {nd }}$ Ed.). Oxfords: Blackwell Publishing

Jaspal, R. \& Breakwell, G. M. (2014). Identity process theory: Identity, social action and social change. Cambridge University Press.

Jaspal, R. \& Cinnirella, M. (2010). Coping with potentially incompatible identities: Accounts of religious, ethnic, and sexual identities from British Pakistani men who identify as Muslim and gay. British Journal of Social Psychology, 49(4), 849-870.

Jim, H.., Pustejovsky, J. E., Park, C. L., Danhauer, S. C., Sherman, A. C., Fitchett, G., Merluzzi, T., Munoz, A., Snyder, M. A. \& Salsman, J. M. (2015). Religion, spirituality, and physical health in cancer patients: A meta-analysis. Cancer, 121(21), 3760-3768.

Joffe, H. (2007). Identity, self-control, and risk. In Social representations and identity (pp. 197-213). Palgrave Macmillan, New York.

Koenig, H. G., McCullough, M. E., \& Larson, D. (2001). Religion and health. New York, NY: Oxford University Press Inc, 1, 276-291. 
Loewenthal, K. M. (2007). Religion, culture and mental health. Cambridge University Pres.

Loewenthal, K. M. (2014). Religion, identity and mental health. Identity Process Theory: Identity, Social Action and Social Change, 316.

Morrisey, G., \& Higgs, J. (2006). Phenomenological research and adolescent female sexuality: Discoveries and applications. Qualitative Report, 11(1), 161-181.

Okulicz-Kozaryn, A. (2010). Religiosity and life satisfaction across nations. Mental Health, Religion \& Culture, 13(2), 155-169.

Paiva, C. E., Paiva, B. S. R., Yennurajalingam, S., \& Hui, D. (2014). The Impact of Religiosity and Individual Prayer Activities on Advanced Cancer Patients' Health: Is There Any Difference in Function of Whether or Not Receiving Palliative Antineoplastic Therapy?. Journal of religion and health, 53(6), 1717-1727.

Pargament, K. I., Koenig, H. G., \& Perez, L. M. (2000). The many methods of religious coping: Development and initial validation of the RCOPE. Journal of clinical psychology, 56(4), 519-543.

Patton, M. Q. (1990). Qualitative evaluation and research methods. SAGE Publications, inc.

Pehrson, S., \& Reicher, S. (2014). On the meaning, validity and importance of the distinction between personal and social identity: a social identity perspective on Identity Process Theory. Identity Process Theory, 97-117.

Richardson, J. T. (2007). A critique of "brainwashing" claims about new religious movements. Cults and new religious movements: A reader, 160-166.

Robbins, T. (1988). Cults, converts and charisma: The sociology of new religious movements. Sage Publications, Inc.

Salsman, J. M., Brown, T. L., Brechting, E. H., \& Carlson, C. R. (2005). The link between religion and spirituality and psychological adjustment: The mediating role of optimism and social support. Personality and social psychology bulletin, 31(4), 522-535.

Salsman, J. M., Pustejovsky, J. E., Jim, H. S., Munoz, A., Merluzzi, T. V., Park, C. L., Danhause, S. C., Sherman, A. C., Snyder, M. A. \& Fitchett, G. (2015). A meta-analytic approach to examining the correlation between religion/spirituality and mental health in cancer. Cancer, 121(21), 3769-3778.

Saroglou, V., Christians, L., Buxant, C., \& Casalfiore, S. (2006). Belgian science policy, current problems concerning social cohesion: Contested religious movements, psychology, law and policies of precaution. Faculty of Law and Centre for Psychology of Religion, Catholic University Leuven.

Shaw, R. L. (2004). Making sense of violence: A study of narrative meaning. Qualitative Research in Psychology, 1(2), 131-151.

Twigger-Ross, C. L., \& Uzzell, D. L. (1996). Place and identity processes. Journal of environmental psychology, 16(3), 205-220. 
Unterrainer, H. F., Lewis, A. J., \& Fink, A. (2014). Religious/spiritual well-being, personality and mental health: a review of results and conceptual issues. Journal of religion and health, 53(2), 382-392.

Vignoles, V. L., Chryssochoou, X., \& Breakwell, G. M. (2002). Evaluating models of identity motivation: Self-esteem is not the whole story. Self and Identity, 1(3), 201-218.

Walters, K. A., \& Auton-Cuff, F. P. (2009). A story to tell: The identity development of women growing up as third culture kids. Mental Health, Religion and Culture, 12(7), 755-772.

Wengraf, T. (2001). Qualitative research interviewing: Biographic narrative and semistructured methods. Sage. 